\title{
Neonatal double switch for congenitally corrected transposition with Ebstein anomaly and bilateral superior venae cavae
}

\author{
Vinod A. Sebastian, MD, ${ }^{\mathrm{a}}$ Andrea Cooley, DO, ${ }^{\mathrm{a}}$ Claudio Ramaciotti, MD, \\ Kristine J. Guleserian, MD, ${ }^{a}$ and Joseph M. Forbess, MD, ${ }^{a}$ Dallas, Tex
}

Congenitally corrected transposition of the great arteries (ccTGA) is a complex cardiac defect with discordant atrioventricular and ventriculoarterial connections. Anatomic correction with the double switch procedure is traditionally done beyond the neonatal period. For patients in whom the morphologically left ventricle (LV) has been exposed to lower pulmonary artery (PA) pressure, the LV must be "retrained" with PA banding to increase LV afterload. Surgical retraining only improves LV systolic function, however, potentially at the expense of impairing diastolic function and promotion of pathologic ventricular mass. ${ }^{1}$ In addition, initial PA banding may negatively affect eventual anatomic repair of ccTGA as a result of branch PA distortion, pulmonary root distortion with the potential for neoaortic valve dysfunction, and the not infrequent need for band adjustment procedures. Theoretically, a neonatal double switch could eliminate both the surgical morbidity of PA banding and the deleterious functional consequences from LV retraining. We describe the surgical management of a neonate with ccTGA, Ebstein anomaly of the tricuspid valve, and bilateral superior vena cavae.

\section{CLINICAL SUMMARY}

A 3.4-kg term male neonate was brought to us after a fetal diagnosis of ccTGA $\{\mathrm{S}, \mathrm{L}, \mathrm{L}\}$ with Ebstein anomaly of the tricuspid valve. Echocardiography showed mild tricuspid regurgitation and bilateral superior vena cava. The left superior vena cava drained into an intact coronary sinus. We performed a double switch (Senning and arterial switch procedure) at 5 days of age by means of a completely autologous tissue-based technique for atrial inversion. The coronary sinus was unroofed and both the roof of the coronary sinus and the septum primum flap were used to create the posterior wall of the systemic

\footnotetext{
From the Division of Pediatric Cardiac Surgery, ${ }^{\mathrm{a}}$ Department of Cardiovascular and Thoracic Surgery, and the Division of Pediatric Cardiology, ${ }^{\mathrm{b}}$ Children's Medical Center of Dallas, UT Southwestern Medical Center at Dallas, Dallas, Tex.

Disclosures: Authors have nothing to disclose with regard to commercial support.

Received for publication May 28, 2014; revisions received Aug 28, 2014; accepted

for publication Sept 7, 2014; available ahead of print Oct 3, 2014.

Address for reprints: Vinod A. Sebastian, MD, 1935 Medical District Dr, Suite

C3.211, Dallas, TX 75235 (E-mail: vinod.sebastian@utsouthwestern.edu).

J Thorac Cardiovasc Surg 2014;148:e241-2

$0022-5223 / \$ 36.00$

Copyright (c) 2014 by The American Association for Thoracic Surgery

http://dx.doi.org/10.1016/j.jtcvs.2014.09.006
}

venous pathway (Figure 1, $A$ and $B$ ). The right atrial free wall was used to complete the anterior wall of the systemic venous pathway to the tricuspid valve (Figure 1,C), and an in situ pericardial flap (Figure 1,D) was used to complete and augment the pulmonary venous pathway from a right-sided pulmonary venotomy to the mitral valve. The arterial switch was performed in the usual fashion; however, the neopulmonary artery anastomosis was performed onto the left PA because of the leftward position of the aorta (neopulmonary artery). The aortic crossclamp time was 132 minutes, and total cardiopulmonary bypass time was 182 minutes. The patient underwent delayed sternal closure on postoperative day 1 . He was reintubated on postoperative day 3 and chest fluoroscopy showed right diaphragm paralysis, so he underwent right diaphragmatic plication. The total duration of mechanical ventilation was 10 days, intensive care unit stay was 22 days, and total hospital stay was 30 days. Echocardiography at 2 months of age showed no Senning obstruction, normal semilunar and atrioventricular valve function, and normal biventricular function.

\section{DISCUSSION}

The neonatal double switch for ccTGA with intact ventricular septum results in anatomic correction, with subsequent physiologic hyperplasia and hypertrophy of the growing morphologic LV. The traditional approach, with a delayed double switch, requires additional surgical procedures to "retrain" the LV. Delays in anatomic correction can lead to tricuspid regurgitation and right ventricular dysfunction, both of which are a risk factor for mortality. ${ }^{2}$ Even in neonates with symptoms, palliative PA bands or systemic-PA shunts are performed, thus delaying definitive repair and subjecting patients to significant morbidity and mortality. PA banding before arterial switch in D-transposition, for example, has been associated with delayed aortic root dilation and neoaortic regurgitation. ${ }^{3}$

Historically, the neonatal Senning operation for D-transposition of the great arteries has been associated with good short-term and midterm survivals. ${ }^{4}$ We considered that the addition of this procedure to an arterial switch in an unoperated mediastinum was a reasonable proposition. In addition, we were encouraged to perform the neonatal double switch in this patient by the presence of Ebstein anomaly and the potential morbidity that can result for patients with ccTGA who have this additional abnormality. Early transition 


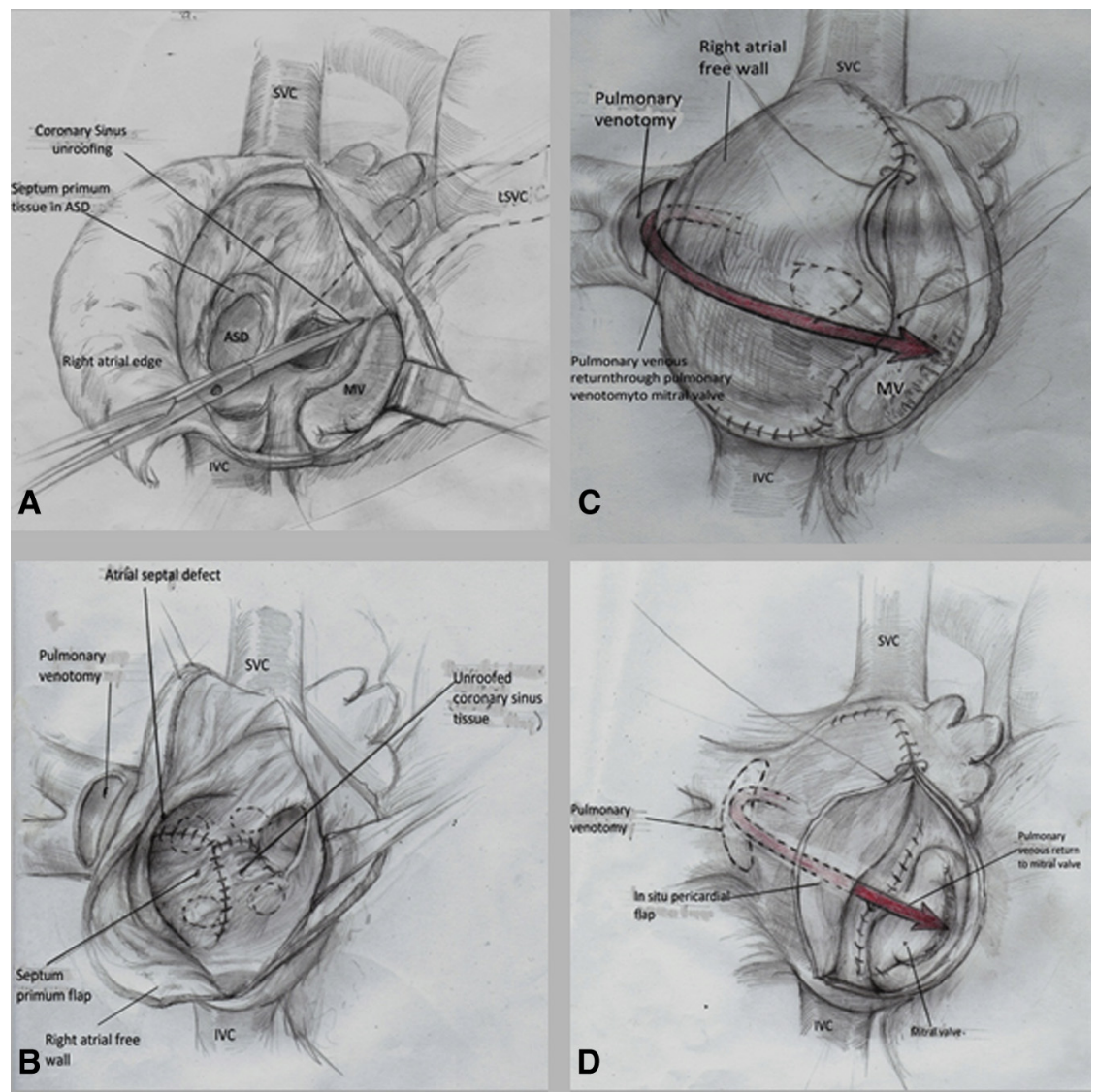

FIGURE 1. Technique of neonatal double switch. A, The coronary sinus is unroofed. B, The coronary sinus roof and mobilized septum primum flap are used to make the posterior wall of the systemic venous baffle. C, The right atrial free wall is used to complete the systemic venous baffle to the tricuspid valve. D, In situ pericardium is used to baffle the pulmonary venous blood from the right pulmonary venotomy to the mitral valve. $S V C$, Superior vena cava; $A S D$, atrial septal defect; $L S V C$, left superior vena cava; $M V$, mitral valve; $I V C$, inferior vena cava.

of this valve to a subpulmonary inlet function, and away from systemic pressure, could be beneficial.

Development of LV dysfunction, arrhythmias, and neoaortic insufficiency have all been reported after anatomic repair of ccTGA. We propose that LV and neoaortic valve function may be preserved with a neonatal anatomic correction.

\section{CONCLUSIONS}

The neonatal double switch procedure can be safely accomplished, even in a complex variant associated with bilateral venae cavae and Ebstein anomaly. Our technique of fully autologous tissue-based repair allows for growth potential of the atrial baffles. The neonatal double switch has previously been reported only in neonates with symptoms. ${ }^{5}$ With increasing surgical experience, however, neonatal anatomic repair may be applicable to a wider number of patients with ccTGA.

\section{References}

1. Bishop SP, Melsen LR. Myocardial necrosis, fibrosis and DNA synthesis in experimental cardiac hypertrophy induced by sudden pressure overload. Circ Res. 1976;39:238-45.

2. Prieto LR, Hordof AJ, Secic M, Rosenbaum MS, Gersony WM. Progressive tricuspid valve disease in patients with congenitally corrected transposition of the great arteries. Circulation. 1998;98:997-1005.

3. Schwartz ML, Gauvreau K, del Nido P, Mayer JE, Colan SD. Long-term predictors of aortic root dilatation and aortic regurgitation after arterial switch operation. Circulation. 2004;110(Suppl 1):II128-32.

4. deLeon VH, Hougen TJ, Norwood WI, Lang P, Marx GR, Castaneda A. Results of the Senning operation for transposition of the great arteries with intact ventricular septum in neonates. Circulation. 1984;70(3 Pt 2):121-5.

5. Bautista-Hernandez V, Serrano F, Palacios JM, Caffarena JM. Successful neonatal double switch in symptomatic patients with congenitally corrected transposition of the great arteries. Ann Thorac Surg. 2008;85:e1-2. 